\title{
PENG ARUH BRAND IMAGE DAN EXPERIENTIAL MARKETING TERHADAP CUSTOMER SATISFACTION (STUDI PADA HOTEL OYO SURABAYA)
}

\author{
Ilham Anjas Wahyudi ${ }^{*}$ \\ Jurusan Manajemen, Universitas Negeri Surabaya \\ Email: ilhamanjas1111@gmail.com \\ *penulis korespondensi
}

\begin{abstract}
ABSTRAK
Penelitian ini bertujuan untuk mengetahui adakah pengaruh antara brand image dan experiential marketing sebagai variabel independen terhadap kepuasan pelanggan sebagai varibel dependen pada hotel OYO di Surabaya. Penelitian ini menggunakan metode quantitative dengan responden 110 orang yang berusia $18-50$ tahun. Kuesioner one-onone diterapkan pada pelanggan hotel OYO yang pernah menginap minimal 1 kali di hotel OYO di Surabaya. Setelah dilakukan uji validitas dan reliabilitas indikator penelitian, maka dilakukan uji hipotesis. Teknik analisis data yang digunakan adalah regresi linier berganda. Instrumen penelitan berupa observasi, wawancara, dan kuesioner dianalisis menggunakan skala likert. Hasil peenlitian menunjukkan bahwa citra merek tidak berpengaruh terhadap kepuasan konsumen, tetapi berbeda dengan experiential marketing yang berpengaruh positif terhadap kepuasan konsumen.
\end{abstract}

Kata Kunci: Brand image, Experiential marketing, Customer satisfaction, Hotel OYO, Virtual Hotel Operator.

\section{ABSTRACT}

This study aims to research is there any influence between brand image and experiental marketing as independent variable to customer satisfaction as dependent variable in OYO Hotels in Surabaya. This study used quantitavie method and using 110 people as a respondents with a vulnerable age of 18-50 years. In the context of this field research, an one-on-one quistionnare has been applied on customer OYO hotels people who have stay at least 1 time in OYO Hotels in Surabaya. After testing the validation and reliability of the research indicators, a hypothesis test was conducted. The technique to analyse of this research was regression linier. Instrument this research are observation, interview, and questionniare that analyzed using likert scale This research's result showed that brand image does not influence customer satisfaction, but the different result was founded thah experiential marketing influence significantly to customer satisfaction.

Keywords: Brand Image, Experiential marketing. Customer satisfaction, Hotel OYO, Virtual Hotel Operator.

\section{PENDAHULUAN}

\section{Latar Belakang}

Industri Pariwisata kini memiliki daya tarik lebih dimata para wisatawan baik nusantara maupun mancanegara. Oleh karena itu banyak tempat-tempat sengaja dikembangkan agar mampu menarik kunjungan para wisatawan. Menurut bps.go.id jumlah kunjungan Wisatawan Mancanegara selama periode januari - juni 2019 berjumlah 7.828.224. Jumlah ini meningkat sebesar 4\% dari periode januari - juni 2018 yang berjumlah 7.525.468. Untuk terus meningkatkan jumlah kunjungan wisata tersebut, pemerintah Indonesia dan seluruh lembaga lain berupaya meningkatkan seluruh elemen serta potensi dari masing-masing pariwisata yang terdapat di setiap daerah. Dilansir dalam liputan6.com, sebagai ibukota Jawa Timur, Surabaya memiliki banyak pilihan tempat wisata yang dapat dikunjungi kala berlibur. Setiap tahun, jumlah wisatawan yang datang ke kota Surabaya terus meningkat. Baik wisatawan dalam negeri maupun luar negeri. Menurut surabaya.bisnis.com tingkat kunjungan wisatawan mancanegara ke Jawa Timur pada Juli 2019 mengalami peningkatan sebesar 8,61\% yang diperkirakan karena para wisatawan datang untuk menikmati musim panas. Menurut BPS Jatim, jumlah kunjungan 
wisatawan mancanegara pada bulan Juli 2019 mencapai 25.143 kunjungan dibandingkan pada bulan juni yang hanya 23.150 kunjungan. Wisatawan mancanegara yang berkunjung ke Indonesia terdiri dari beberapa daerah terdekat dari Indonesia seperti Malaysia, Singapura, Tiongkok, Australia dan Timor Leste.

Bicara terkait potensi pariwisata setiap daerah yang mengakibatkan banyak kunjungan dari para wisatawan baik nusantara maupun lokal, maka usaha dibidang penginapan atau hotel juga dilihat sebagai peluang untuk di kembangkan. Menurut bps.go.id pada bulan Juni 2019 Tingkat Penghunian kamar (TPK) hotel klasifikasi bintang di Indonesia sebesar 52,27\% atau meningkat 0,23\% dar tahun 2018 sebesar 52,4\%. Dilansir dalam kanal24.co.id, Badan Pusat Statistika Jatim mencatat Tingkat Penghunian Kamar (TPK) hotel berbintang di Jawa Timur pada bulan Agustus 2020 mencapai $34,17 \%$ atau naik 5,60 poin dari bulan sebelumnya. Sementara, Rata-rata Lama Menginap Tamu (RLMT) Asing pada hotel berbintang pada bulan agustus mencapai 3,34 hari atau naik 0,08 poin dibandingkan bulan juli 2020 yang mencapai 3,26 hari.

Meski kebutuhan akan penginapan yang tinggi telah teratasi dengan ketersediaan hotel, namun sistem yang ada harus tetap kompetitif dengan konsep yang lebih efektif dan efisien. Hadirnya teknologi dengan bentuk Virtual Hotel Operator (VHO) telah sangat membantu menciptakan sistem yang efektif dan efisien pada sektor bisnis perhotelan. VHO adalah sebuah platform daring yang menampilkan daftar berbagai jenis penginapan disuatu daerah sehingga para calon wisatawan dapat mengetahui berbagai hotel pada disuatu daerah (Wiastuti, 2016), melalui VHO calon wisatawan dapat melakukan pemesanan kamar melalui daring, dengan VHO juga para pebisnis memiliki sistem yang lebih terstruktur. Salah satu perusahaan VHO yang terkenal adalah perusahaan OYO Hotels, OYO adalah perusahaan dengan basis teknologi pertama di India yang bergerak dibidang perhotelan (Jesu , 2018). OYO memulai bisnisnya pada tahun 2012 dan kini telah menjadi rantai hotel (Jesu , 2018), adapun tujuan dari perusahaan startup ini adalah mengubah cara orang melakukan penginapan diluar rumahnya.

Kehadiran OYO di Surabaya telah sangat membantu perusahaan hotel di Surabaya, Pemilik hotel mengaku rata-rata okupansi hotel naik hingga 75 persen sejak bergabung dengan jaringan OYO (https://surabaya.tribunnews.com/). Peningkatan pesat suatu perusahaan yang sangat signifikan bukan berarti perusahaan tidak perlu memikirkan kepuasan pelanggan, meskipun telah menggunakan sistem berbasis teknologi industri travel termasuk hotel sejatinya berada dibawah ancaman dari berbagai kekuatan disrupsi yang ada (Watkins, 2020). Dalam berahan di era disrupsi perusahaan harus mampu memuaskan pelanggan dengan memahami consumer behavior. Kemampuan hotel OYO dalam menghadapi era disrupsi bahkan menjadi perusahaan raksaksa yang mampu meningkatkan okupansi hotel secara signifikan menjadi dasar ketertarikan peneliti untuk menjadikan hotel OYO sebagai obyek penelitian.

Brand adalah salah satu faktor yang menentukan kesuksesan suatu produk (Subaebasni et al., 2019) terlebih dimasa depan dimana setiap perusahaan akan sangat bergantung pada merek. Kuatnya brand image akan sangat membantu terkait peningkatan reputasi perusahaan, kemampuan arus finansial, tingkat okupansi, harga, omset, serta profit (So et al., 2013). Untuk menciptakan kepuasan pelanggan, perusahaan juga harus mampu memberikan pelayanan yang berkualitas, dengan memberikan experience yang memungkinkan customer menikmati kesenangan dan perasaan pengalaman dalam prosesnya (Yeh et al., 2019) .

Saleem \& Raja, (2014) dan Öztürk, (2015) melakukan penelitian dimana ditemukan pengaruh positif secara signfikan pada variabel brand image terhadap variabel customer satisfaction 
dengan variabel experiential marketing sebagai variabel intervening. Adapun penelitian oleh Araci et al (2017) menghasilkan temuan terdapat beberapa dimensi variabel experiential marketing berupa sense, think, dan act yang hasil pengaruhnya negatif terhadap variabel customer satisfaction, penelitian lain dilakukan oleh Milman \& Adi (2018) menunjukan adanya pengaruh negatif antara experiential marketing pada dimensi think dan act terhadap customer satisfaction.

Brand OYO sebagai salah satu brand Virtual Hotel Online yang ada di Surabaya memiliki brand yang kuat dan memberikan experience bagi pelangganya sehingga dapat memuaskan pelanggan sehingga tujuan penelitian ini menguji korelasi variabel brand image, experiential marketing terhadap variabel customer satisfaction pada Hotel OYO di Surabaya.

\section{Kajian Pustaka dan Pengembangan Hipotesis Customer satisfaction}

Customer satisfaction adalah kondusifitas dalam upaya mempromosikan perilaku pelanggan saat melakukan konsumsi suatu produk (Cardozo, 1965). Yap et al (2012) mengartikan customer satisfaction adalah sebuah evaluasi yang terjadi pasca transaksi terjadi sebagai alternatif untuk mengetahui dan mengevaluasi apakah pelanggan mendapatkan kepuasan sesuai dengan harapannya atau melebihi ekspetasinya, sedangkan ketidakpuasan terjadi saat hasil yang diperoleh dibawah ekspetasi pelanggan. Konsep ini lebih cenderung dalam upaya memastikan pelanggan akan kembali daripada mendapatkan pelanggan yang baru.

Dalam mengukur variabel costumer satisfaction, peneliti mengacu kepada Kotler dan Keller (2009) dimana terdapat 4 dimensi, yaitu :

1. Kesesuaian kualitas pelayanan dengan tingkat harapan

2. Keinginan pelanggan membeli produk kembali

3. Pelanggan tidak memberikan keluhan

\section{Brand Image}

Di era globalisasi ini persaingan antar bisnis terus meningkat, keinginan dan kebutuhan konsumen sebagaimana kebiasaan membeli mereka membuat konsep merk menjadi fenomena yang penting, maka dari itu menciptakan persepsi merk yang kuat adalah prioritas utama di era sekarang ini (Durmaz et al., 2018). Saleem \& Raja (2014) mendifinisikan bahwa brand image adalah sebuah konsep atau cara bagaimana customer mengingat merk akan suatu produk dengan cara yang mudah, pada dasarnya brand image merupakan hal pertama yang diingat oleh customer saat mereka melakukan transaksi.

Kotler \& Keller ( 2013) menyatakan Customer satisfaction merupakan nilai kepuasan yang didapat setelah pelanggan membandingkan yang dia dapat dengan ekspetasi sebelum transaksi terjadi. Kualitas produk menurut Hamdani, (2014) adalah tingkat kemampuan produk atau layanan dalam memenuhi spesifikasinya. Konsistensi kualitas suatu produk atau layanan dapat berkontribusi pada keberhasilan suatu perusahaan.

Brand Image merupakan simbol dari persepsi pelanggan terhadap suatu merk produk. Semakin baik citra yang ada pada pelanggan terhadap suatu merk akan berdampak pada kemungkinan loyalitas pelanggan. Subaebasni et al (2019) melakukan penelitian dan menemukan pengaruh positif antara brand image dengan customer satisfaction, bahkan juga berpengaruh terhadap customer loyality, hal serupa juga bisa dijumpai pada penelitian yang dilakukan oleh Neupane (2015) juga menemukan korelasi positif antara brand image dengan customer satisfaction yang dilakukan di retail supermarket UK. 
Berdasarkan hasil peneliti terdahulu, maka hipotesis yang dapat dibentuk adalah:

H1 : Brand Image berpengaruh positif terhadap Customer satisfaction hotel OYO di Surabaya.

\section{Experiential marketing}

Untuk menciptakan kepuasan pelanggan, perusahaan juga harus mampu memberikan pelayanan yang berkualitas, selain itu bisnis yang ada juga menerapkan experience yang memungkinkan customer menikmati kesenangan dan perasaan pengalaman dalam prosesnya (Dewi, 2015). Lee \& Kang (2015) mendefinisikan experiential marketing sebagai seorang pelanggan yang merasakan rangsangan tertentu berdasarkan pengamatan atau partisipasi dalam suatu peristiwa dan diinduksi motivasi untuk memaparkan pemikirannya dan mendahului perilaku konsumtif nya agar lebih meningkatkan nilai produk.

Pengalaman akan layanan yang diberikan sangat menentukan apakah customer merasa puas atau tidak (Yeh et al., 2019), teori itu diperkuat berdasarkan hasil penelitian nya yang hasil temuan Yeh et al (2019) yang menemukan korelasi positif antara pengalaman layanan dengan kepuasan pelanggan.

Pelanggan yang memiliki kesan atas pengalaman pembelian barang atau jasa menjadikan hal tersebut sebagai pengalaman yang menyenangkan. Ketika suatu pengalaman itu dapat mencuri perhatian pelanggan, maka pengalaman tersebut dikenang sebagai pengalaman yang menyenangkan.

Saat Experiential marketing terjadi, pelanggan merasakan pengalaman mengesankan yang melebihi harapannya maka terjadi kepuasan pelanggan. Hal ini terjadi karena pengalaman yang menyenangkan ketika pelanggan mengonsumsi produk dapat menyentuh emosi positif, secara otomatis memberikan kepuasan pada pelanggan tersebut.

Albert (2012) melakukan penelitian dan menemukan adanya pengaruh positif pada variabel experiential marketing pada customer satisfaction. Yeh et al (2019) menghasilkan temuan adanya korelasi positif variabel experiential marketing dan kepuasan pelanggan pada perusahaan pariwisata Taiwan. Namun juga ditemukan penelilitian dengan variabel serupa dan memiliki hasil yang berbeda seperti Araci et al (2017) melalukan penelitian dimana pada Dimensi variabel $\mathrm{X}$ yaitu sense, think, act berpengaruh negatif. Penelitian yang dilakukan oleh Milman \& Adi (2018) menunjukan bahwa terdapat pengaruh negatif antara experiential marketing pada dimensi think dan act terhadap customer satisfaction.

Berdasarkan hasil penelitian terdahulu, maka hipotesis yang dapat dibentuk adalah:

$\mathrm{H} 2$ : Experiential marketing berpengaruh positif terhadap Customer satisfaction hotel OYO di Surabaya

Dari kedua hipotesis yang telah dibentuk, maka model penelitian dapat dilihat pada gambar 1.

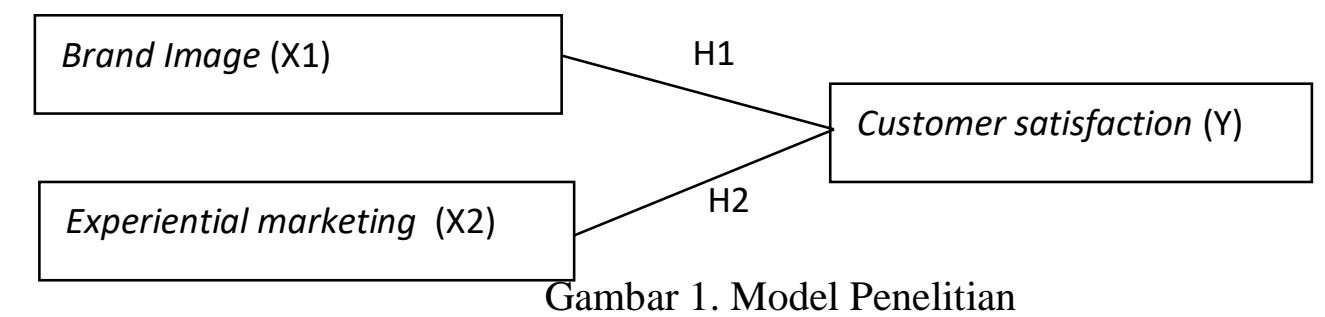




\section{METODE PENELITIAN}

Penelitian kali ini berjenis penelitan asosiatif dengan menggunakan data kuantitatif. Didalam penelitian ini peneliti memperoleh data primer melalui metode observasi pada obyek penelitian serta dengan menyebarkan kuisioner, adapun data sekunder didapat melalui buku, jurnal, dan internet. Dalam upaya mengetahui tingkat kepuasan pelanggan maka karakteristik populasi pada penelitian ini adalah seseorang yang pernah menjadi konsumen hotel OYO Surabaya, dan setidaknya memiliki umur 18 tahun hingga 50 tahun. Hal ini menjadi penting karena mereka yang sudah berpegalaman dan berumur yang mampu mengetahui secara komperhensif intensitas kepuasan yang mereka dapatkan selama bermalam di hotel OYO. Sampel pada penelitian ini berjumlah 115 responden. Dalam memberikan data, responden mengekspresikannya melalui angka dengan menggunakan skala likert sehingga data dapat diolah. Data yang telah diperoleh diolah menggunakan teknik regresi linier berganda dengan bantuan software pengolah data SPSS. Dimensi dan indikator yang digunakan untuk mengukur variabel Brand Image, Experiential marketing dan Customer satisfaction dalam penelitian ini merupakan dimensi dan indikator yang telah disesuaikan dengan obyek penelitian (tabel 1).

Tabel 1. Dimensi dan Indikator Penelitian

Sumber: beberapa artikel, diolah peneliti

\begin{tabular}{|c|c|c|c|}
\hline Variabel & Peneliti & Dimensi & indikator \\
\hline \multirow{6}{*}{$\begin{array}{l}\text { Brand } \\
\text { Image }\end{array}$} & \multirow{6}{*}{$\begin{array}{l}\text { Keller } \\
(2003)\end{array}$} & Brand Strenght & Terdapat berbagai jenis pilihan kamar \\
\hline & & & Harga terjangkau \\
\hline & & Brand & Logo mudah diingat \\
\hline & & Favorability & Familiar \\
\hline & & & Terkenal \\
\hline & & $\begin{array}{l}\text { Brand } \\
\text { Uniqueness }\end{array}$ & Terdapat fasilitas yang unik \\
\hline \multirow{8}{*}{$\begin{array}{l}\text { Experientia } \\
l \text { marketing }\end{array}$} & \multirow{8}{*}{$\begin{array}{l}\text { Schmit } \\
\mathrm{t} \\
(1999)\end{array}$} & Sense & Desain interior yang unik \\
\hline & & & Wangi yang khas \\
\hline & & Feel & Merasa nyaman \\
\hline & & & Menikmati suasana \\
\hline & & Think & Peraturan mudah dipahami \\
\hline & & & Mudah ditemukan dan dijangkau \\
\hline & & Act & $\begin{array}{l}\text { Respon pelayanan terhadap keluhan yang baik } \\
\text { Pilihan sesuai keinginan }\end{array}$ \\
\hline & & Relate & $\begin{array}{l}\text { Membagikan info kepada orang lain melalui sosial } \\
\text { media } \\
\text { Suasana ramah }\end{array}$ \\
\hline \multirow{3}{*}{$\begin{array}{l}\text { Customer } \\
\text { satisfaction }\end{array}$} & \multirow{3}{*}{$\begin{array}{l}\text { Kotler } \\
\& \\
\text { keller } \\
(2009)\end{array}$} & & Merasa puas \\
\hline & & & Memenuhi kebutuhan \\
\hline & & & Melebihi harapan \\
\hline
\end{tabular}

\section{HASIL DAN PEMBAHASAN}

\section{Uji Validitas dan Reliabilitas}

Uji validitas dan reliabilitas dilakukan untuk memastikan bahwa item pernyataan yang digunakan dalam kuesioner telah valid dan reliabel sehingga layak untuk digunakan dalam penelitian. Adapaun hasil uji validitas dan reliabilitas pada penelitian ini menunjukkan bahwa 
seluruh item pernyataan telah valid karena nilai correlated item total atau $\mathrm{r}$ hitung $>\mathrm{r}$ tabel dan bernilai positif sedangkan dinyatakan reliabel karena nilai cronbach's alpha $>0,70$.

\section{Uji Asumsi Klasik}

Sebelum dilakukan uji regresi linier, peneliti telah melakukan uji asumsi klasik yang terdiri dari uji normalitas dengan nilai signifikansi diatas 0,05 dan berdistribusi normal, uji multikolinearitas melalui uji VIF dengan hasil nilai VIF $<10$ sehingga dinyatakan tidak terjadi gejala multikolinearitas dan uji heterokedasitas dengan nilai $\mathrm{t}$ hitung $<\mathrm{t}$ tabel dengan nilai 1,659 sehingga dapat disimpulkan tidak terjadi gejala heterokedasitas. Berdasarkan hasil analisis tersebut maka dapat disimpulkan bahwa data peenlitian bersifat layak untuk dilakukan dalam uji selanjutnya yaitu uji regresi linier.

\section{Uji Kelayakan Model}

Tabel 2. Uji koefisien Determinasi

Sumber: data primer, diolah peneliti

\begin{tabular}{ccccc}
\hline Model & R & R Square & $\begin{array}{c}\text { Adjusted } \\
\text { R Square }\end{array}$ & $\begin{array}{c}\text { Std. Error of the } \\
\text { Estimate }\end{array}$ \\
\hline 1 & 0,436 & 0,190 & 0,175 & 1,78729 \\
\hline
\end{tabular}

Berdasarkan hasil uji koefien determinasi diperoleh nilai $\mathrm{R}$ square sebesar 0,190 atau sebesar 19\%. Nilai tersebut menjelaskan bahwa kontribusi untuk hubungan struktural dari variabel brand image dan experiential marketing terhadap customer satisfaction sebesar 19\% sedangkan $81 \%$ lainnya dijelaskan oleh variabel lain yang tidak termasuk dalam model penelitian.

\section{Deskripsi Responden}

Setelah data dinaytakan memenuhi seluruh syarat penelitian, maka dilakukan uji statistik deskriptof untuk mengetahui karakteristik responden dalam penelitian. Hasil karakteristik responden dalam penelitian ini dapat dilihat pada tabel 2 .

Tabel 3. Karakteristik Responden

Sumber: data primer, diolah peneliti

\begin{tabular}{|c|c|c|}
\hline \multicolumn{3}{|l|}{$\mathrm{N}=110$} \\
\hline Karakteristik Responden & Jumlah & Presentase \\
\hline \multicolumn{3}{|l|}{ Usia } \\
\hline $19-29$ tahun & 70 & $63,3 \%$ \\
\hline $26-30$ tahun & 19 & $17,2 \%$ \\
\hline $30-35$ tahun & 16 & $14,5 \%$ \\
\hline $36-40$ tahun & 6 & $5,5 \%$ \\
\hline $41-45$ tahun & 0 & $0 \%$ \\
\hline 46 - 50 tahun & 0 & $0 \%$ \\
\hline$>51$ tahun & 0 & $0 \%$ \\
\hline \multicolumn{3}{|l|}{ Jenis Kelamin } \\
\hline Laki - laki & 51 & $46,4 \%$ \\
\hline Perempuan & 59 & $53,6 \%$ \\
\hline \multicolumn{3}{|l|}{ Profesi } \\
\hline Mahasiswa/Pelajar & 66 & $60 \%$ \\
\hline PNS & 2 & $1,8 \%$ \\
\hline
\end{tabular}




\begin{tabular}{|c|c|c|}
\hline Wiraswasta & 27 & $25,4 \%$ \\
\hline Pegawai Swasta & 13 & $11,8 \%$ \\
\hline Pegawai BUMN & 2 & $1,8 \%$ \\
\hline Lainnya & 0 & $0,0 \%$ \\
\hline \multicolumn{3}{|l|}{ Penghasilan } \\
\hline$<\mathrm{Rp} 1.000 .000$ & 46 & $41,8 \%$ \\
\hline Rp 1.000.001 - Rp 1.500 .000 & 29 & $26,3 \%$ \\
\hline $\operatorname{Rp} 1.500 .001-\operatorname{Rp} 2.000 .000$ & 14 & $12,7 \%$ \\
\hline $\operatorname{Rp} 2.000 .001-\operatorname{Rp} 3.000 .000$ & 15 & $13,6 \%$ \\
\hline Rp 3.000.001 - Rp 5.000.000 & 24 & $21,8 \%$ \\
\hline Rp 5.000.001 - Rp 7.000.000 & 9 & $8,2 \%$ \\
\hline$>\mathrm{Rp} 7.000 .000$ & 3 & $2,7 \%$ \\
\hline \multicolumn{3}{|l|}{ Jumlah Kunjungan } \\
\hline 1 kali & 69 & $62,7 \%$ \\
\hline$>1 \mathrm{kali}$ & 41 & $37,3 \%$ \\
\hline
\end{tabular}

Pada penelitian ini mayoritas responden terdiri dari responden usia $19-29$ tahun sebesar 63,3\% dengan jenis kelamin perempuan sebesar 53,6\%, berprofesi sebagai mahasiswa/pelajar sebesar $60 \%$, berpenghasilan $<\mathrm{Rp} 1.000 .000$ sebesar $41,8 \%$ serta mengunjungi sebanyak 1x sebesar $62,7 \%$.

\section{Hasil Analisis Regresi Linier Berganda}

Hasil dari pengolahan data analisis regresi linier berganda berfungsi untuk mengetahui pengaruh variabel brand images dan experiential marketing terhadap customer satisfaction hotel OYO di kota Surabaya. Hasil analisis regresi linier berganda dapat dilihat pada tabel 4.

Tabel 4. Hasil Analisis Regresi Linier Berganda

Sumber: data primer, diolah peneliti

\begin{tabular}{lllc}
\hline & \multicolumn{2}{c}{ Variabel A } & $\mathrm{B}$ \\
& & & 7,488 \\
\hline Brand images & $\longrightarrow$ & Customer satisfaction & $-0,002$ \\
Experiential marketing & $\longrightarrow$ & Customer satisfaction & 0,124 \\
\hline
\end{tabular}

Pada tabel 4, model persamaan regresi linier berganda yang diperoleh adalah:

$$
\mathrm{Y}=\mathbf{7 , 4 8 8}-\mathbf{0 , 0 0 3} \mathrm{X} 1+\mathbf{0 , 1 2 4} \mathrm{X} 2
$$

Keterangan:

$\mathrm{Y}=$ Customer satisfaction

$\mathrm{X} 1=$ Brand images

$\mathrm{X} 2 \quad=$ Experiential marketing

Berdasarkan hasil tersebut dapat diinterpretasikan bahwa nilai konstanta $(\alpha)$ sebesar 7,488. Artinya, besarnya customer satisfaction pada hotel OYO di kota Surabaya sebesar 7,488, maka customer satisfaction hotel OYO di kota Surabaya tidak akan terbentuk tanpa adanya pengaruh dari brand images dan experiential marketing. Selanjutnya untuk nilai konstanta $(\alpha)$ variabel brand images dan experiential marketing sebesar - 0,002 dan 0,124 menunjukkan jika semakin menurun tingkat brand images dari hotel OYO maka akan menurunkan kepuasan dari pelanggan 
terhadap hotel tersebut, dan semakin tinggi tingkat pengalaman terhadap hotel OYO akan semakin meningkatkan pula kepuasan pelanggan terhadap hotel OYO di kota Surabaya.

\section{Uji Hipotesis}

Pada tahap uji hipotesis, dilakukan uji t untuk mengetahui pengaruh antara variabel $\mathrm{x}$ dengan $\mathrm{y}$ secara parsial atau tidak. Hal ini dilakukan dengan cara melakukan perbandingan, hipotesis yang diterima harus memiliki tingkat signifikasnsi $<0,1$. Berikut hasil pengolahan peneliti.

Tabel 5. Uji Hipotesis

Sumber: data primer, diolah peneliti

\begin{tabular}{ccccc}
\hline Variabel & t hitung & Sig. & $\boldsymbol{\beta}$ & Keterangan \\
\hline $\begin{array}{c}\text { Brand images } \rightarrow \text { Customer } \\
\text { satisfaction }\end{array}$ & $-0,033$ & 0,974 & $-0,002$ & H1 Ditolak \\
$\begin{array}{c}\text { Experiential marketing } \rightarrow \\
\text { Customer satisfaction }\end{array}$ & 2,216 & 0,029 & 0,124 & H2 Diterima \\
\hline
\end{tabular}

Tabel diatas menunjukkan bahwa hasil penelitian X1 ke Y menghasilkan nilai koefisien regresi (original sample) sebesar - 0,002 dan tingkat signifikansi sebesar 0,974. Hal ini menunjukkan bahwa X1 secara parsial tidak berpengaruh terhadap Y secara ditingkat 10\%, sehingga diperoleh kesimpulan bahwa $\mathrm{H}_{2}$ ditolak.

Tabel diatas menunjukkan bahwa hasil penelitian $\mathrm{X} 2 \mathrm{ke} \mathrm{Y}$ menghasilkan nilai koefisien regresi (original sample) sebesar 0,124 dan tingkat signifkan sebesar 0,029. Hal ini menunjukkan bahwa $\mathrm{X} 2$ secara parsial berpengaruh terhadap Y secara signifikan ditingkat 5\%, sehingga diperoleh kesimpulan bahwa $\mathrm{H}_{2}$ diterima

\section{Pembahasan}

\section{Pengaruh Brand Image Pada Customer satisfaction}

Brand image adalah sebuah konsep atau cara bagaimana customer mengingat merk akan suatu produk dengan cara yang mudah, pada dasar nya brand image merupakan hal pertama yang diingat oleh customer saat mereka melakukan transaksi. Subaebasni et al (2019) yang menemukan bahwa ada pengaruh positif antara Brand Image dengan customer satisfaction, bahkan juga berpengaruh terhadap customer loyality. Hasil penelitian ini selaras dengan Dewi (2015) dan Budiastari (2016) menemukan tidak adanya pengaruh brand image terhadap customer satisfaction.

Karakteristik responden termasuk dalam kategori poor middle class dimana 41,8\% responden memiliki pengeluaran perbulan < Rp. 1.000.000, dengan range usia 19 hingga 29 tahun dan masih ada di bangku kuliah, brand OYO dirasa masih belum memuaskan bagi mereka. Mereka memiliki ekspektasi besar dari hasil informasi yang ditampilkan di media online karena prosentase perbesar responden mendapatkan informasi dari social media. Sehingga mereka memiliki pengharapan yang tinggi dari informasi social media berupa gambar dan ulasan, sedangkan mereka mungkin kurang memahami perbedayaan fasilitas standart hotel atau penginapan. Dengan pengeluaran < Rp. 1.000 .000 mereka bisa jadi mereka membutuhkan kamar tidak untuk sendiri dan memerlukan harga murah sehingga dibenak konsumen merk OYO masih cenderung mahal dengan fasilitas yang kurang memadai. Hal ini menjadikan konsumen menganggap bahwa harga kamar yang dijual OYO dianggap mahal.

Melalui data yang peneliti dapatkan, harga yang dianggap relatif mahal, fasilitas hotel yang kurang maksimal menyebabkan lemahnya nilai dari brand image, hal ini menjadi penyebab variabel brand image tidak mempengaruhi variabel costumer satisfaction. 


\section{Pengaruh Experiential marketing Terhadap Customer satisfaction}

Kepuasan pelanggan merupakan salah satu hasil sangat vital yang setiap perusahaan jasa berusaha memperolehnya (El-Adly, 2019). Experiential marketing merupakan konsep bagaimana customer merasakan pengalaman berdasarkan perasaan, rangsanagan, pengamatan, pemikiran, dan hubungan saat menikmati suatu produk. Albert (2012) mendapatkan pengaruh positif dalam penelitiannya pada variabel experiential marketing terhadap customer satisfaction. Tsu-Ming (dalam, Yeh et al., 2019) menghasilkan temuan adanya korelasi positif pada variabel experiential marketing dan kepuasan pelanggan pada perusahaan pariwisata Taiwan. Hal serupa terjadi pada penelitian ini dimana ditemukan pengaruh positif secara signfikan pada variabel experiential marketing kepada customer loyalty.

Karakteristik responden yang mayoritas berada diusia 19 hingga 29 tahun lulusan SMA dan sedang berprofesi sebagai mahasiswa merupakan responden yang gemar mengekspolre kebahagiannya, tidak aneh jika nilai tertinggi dengan kategori setuju ditemukan pada indikator relate dengan instrument pernyataan "Saya suka memposting foto saat menginap di hotel OYO", kepuasan yang dimiliki oleh para responden saat bermalam terlebih saat melakukan liburan bersama teman-teman membuat para responden memposting pengalaman mereka, salah satunya saat menginap di hotel OYO, hal ini menjadi relevan ketika 59,1\% responden mengetahui informasi terkait hotel OYO melalui social media karena banyaknya para pengunjung yang memposting tentang hotel OYO. Mengacu pada penelitian konsumen merasa memiliki pengalaman yang baik saat bermalam di OYO dan ini menjadi dorongan pula bagi konsumen untuk membagikan pengalaman menginapnya di social media.

\section{KESIMPULAN DAN SARAN}

Berdasarkan hasil penelitian, dapat disimpulkan bahwa brand images tidak berpengaruh positif terhadap customer satisfaction hotel OYO di kota Surabaya. Sedangkan experiential marketing berpengaruh positif terhadap customer satisfaction hotel OYO di kota Surabaya.

Terdapat implikasi teoritis yang dihasilkan dalam penelitian ini yaitu, brand images tidak mendukung kerangka teoritis bahwa brand images berpengaruh secara positif terhadap customer satisfaction. Sedangkan experiential marketing mendukung kerangka teoritis bahwa experiential marketing berpengaruh positif terhadap customer satisfaction. Selain berdasarkan kerangka teoritis, terdapat implikasi berdasarkan karakteristik responden yang banyak didominasi oleh mahasiswa/pelajar dengan rentang usia 19 - 29 tahun sehingga dapat menjadi peluang bagi pemasar untuk lebih memfokuskan dan memperhatikan brand images dari suatu produk dan bagaimana pengalaman pelanggan serta promosi atau pelayanan kepada customer dengan karakteristik tersebut. Sehingga diharapkan dapat meningkatkan kepuasan pelanggan pada hotel OYO di kota Surabaya.

Penelitian menyadari bahwa hasil penelitian ini sangat terbatas sehingga disarankan untuk peneliti selanjutnya untuk lebih baik jika obyek penelitian dilakukan dengan wilayah yang lebih besar, menggunakan variabel lain sebagai variabel independen agar penelitian lebih mampu memberikan masukan dan mengetahui berbagai variabel yang memperngaruhi kepuasan pelanggan.

Adapun saran untuk perusahaan adalah sebaiknya hotel OYO wilayah Surabaya meningkatkan citra merk dengan ketiga indikator tersebut dalam upaya meningkatkan kepuasan pelanggan, terkhusus pada meningkatkan fasilitas OYO agar bisa lebih digunakan dan harga lebih terasa murah. Sebaiknya perusahaan juga lebih meningkatkan tingkat pengalaman konsumen saat 
bermalam di hotel OYO khususnya Surabaya agar konsumen merasa lebih puas saat bermalam disana.

\section{REFERENSI}

Albert, D. (2012). Experiential marketing Terhadap Customer satisfaction dan Customer Loyalty The Light Cup. October 2018, 2012-2013.

Araci, U. E., Bulut, Z. A., \& Kocak, N. (2017). the Relation Among Experiential marketing, Customer satisfaction, and Behavioral Intention: a Study on Food and Beverage Businesses. 23rd International Scientific Conference on Economic and Social Development, October, 361-371.

Badan Pusat Statistik. (2019). Jumlah kunjungan wisman ke Indonesia Juni 2019 mencapai 1,45 juta kunjungan. Retrieved November 26, 2020, from https://www.bps.go.id/pressrelease/2019/08/01/1615/jumlah-kunjungan-wisman-keindonesia-juni-2019-mencapai-1-45-juta-kunjungan-.html

Badan Pusat Statistik. (2020). BPS: Tingkat Hunian Kamar Hotel Jatim Naik. Retrieved November 26, 2020, from https://kanal24.co.id/read/bps-tingkat-hunian-kamar-hotel-jatimnaik

Budiastari, S. (2016). the Influence of Product Quality , Price Perception and Brand Image on Satisfaction and Customer Loyalty Holcim Concrete Readymix in Jakarta. JRMSI - Jurnal Riset Manajemen Sains Indonesia, 7(2), 345. https://doi.org/10.21009/jrmsi.007.2.08

Cardozo, R. N. (1965). Experimental Study and Expectation ,. Journal of Marketing Research, 2(3), 244-249.

Dewi, L. N. (2015). Analisis Pengaruh Kualitas Produk, Citra Merek, Kepercayaan Dan Kepuasan Terhadap Loyalitas Pengguna Produk Advan Di Kota Semarang. Jurnal Riset Ekonomi, Manajemen, Bisnis Dan Akuntansi, 1-17. http://eprints.dinus.ac.id/17594/

Durmaz, Y., Cavusoglu, S., \& Ozer, O. (2018). The Effect of Brand Image and Brand Benefit on Customer Loyalty: The Case of Turkey. International Journal of Academic Research in Business and Social Sciences, 8(5). https://doi.org/10.6007/ijarbss/v8-i5/4140

El-Adly, M. I. (2019). Modelling the relationship between hotel perceived value, customer satisfaction, and customer loyalty. Journal of Retailing and Consumer Services, 50(xxxx), 322-332. https://doi.org/10.1016/j.jretconser.2018.07.007

Hamdani, L. dan. (2014). Manajemen Pemasaran. 2006.

Kotler, P., \& Keller, K. L. (2013). Philip Kotler, Manajemen Pemasaran Edisi 13 Jilid 1. intro ( PDFDrive.com ).pdf.

Lee, J. S., \& Kang, J. (2015). Fan Identification Effects of Sport Event Satisfaction on. Sport Marketing Quarterly, January 2015.

Melani, A. (2019). Kunjungan Turis Asing ke Jatim Naik 58,46 persen pada Juni 2019. Retrieved November 26, 2020, from https://surabaya.liputan6.com/read/4031938/kunjungan-turis-asing-ke-jatim-naik-5846persen-pada-juni-2019

Milman, Adi, O. (2018). The promise of the 2016 USA-China tourism year: Strategies to boost tourism exchange. Journal of Destination Marketing and Management, 8(October 2016), 423-425. https://doi.org/10.1016/j.jdmm.2017.02.005

Neupane, R. (2015). The Effects of Brand Image on Customer satisfaction and Loyalty Intention in Retail Super Market Chain UK. International Journal of Social Sciences and Management, 2(1), 9-26. https://doi.org/10.3126/ijssm.v2i1.11814

Öztürk, R. (2015). Exploring the Relationships between Experiential marketing, Customer satisfaction and Customer Loyalty: An Empirical Examination in Konya. International Journal of Social, Behavioral, Educational, Economic and Management Engineering, 9(8), 
2485-2488. www.citeulike.org/user/tilljwinkler/article/10083551.

Saleem, H., \& Raja, N. S. (2014). The impact of service quality on customer satisfaction, customer loyalty and brand image: Evidence from hotel industry of Pakistan. Middle - East Journal of Scientific Research, 19(5), 706-711. https://doi.org/10.5829/idosi.mejsr.2014.19.5.21018

So, K. K. F., King, C., Sparks, B., \& Wang, Y. (2013). The influence of customer brand identification on hotel brand evaluation and loyalty development. International Journal of Hospitality Management, 34(1), 31-41. https://doi.org/10.1016/j.ijhm.2013.02.002

Subaebasni, S., Risnawaty, H., Arie Wicaksono, A., Albadriyah Widsata, P., Straitliner Express, P., \& APP Jakarta Kemenperin, P. (2019). International Review of Management and Marketing Effect of Brand Image, the Quality and Price on Customer satisfaction and Implications for Customer Loyalty PT Strait Liner Express in Jakarta. International Review of Management and Marketing, 9(1), 90-97. https://doi.org/10.32479/irmm.7440

Watkins, B. E. (2020). 5 forces disrupting the travel industry. December 2014, 1-2.

Wiastuti, R. (2016). Virtual Hotel Operator; Is It Disruption for Hotel Industry? Jurnal Hospitality Dan Pariwisata 2 (2), 2017, 2(2), 201-213. https://doi.org/10.30813/.v2i2.905

Widarti, P. (2019). Juli 2019, Kunjungan Wisman Ke Jatim Naik 8,61\%. Retrieved November 26, 2020, from surabaya.bisnis.com website: https://www.kemenparekraf.go.id/categories/statistik-wisatawan-mancanegara

Yap, B. W., Ramayah, T., \& Wan Shahidan, W. N. (2012). Satisfaction and trust on customer loyalty: A PLS approach. Business Strategy Series, 13(4), 154-167. https://doi.org/10.1108/17515631211246221

Yeh, T. M., Chen, S. H., \& Chen, T. F. (2019). The relationships among experiential marketing, service innovation, and customer satisfaction-A case study of tourism factories in Taiwan. Sustainability (Switzerland), 11(4), 1-12. https://doi.org/10.3390/su11041041 